direct design of structures by plastic design methods in a sense that is not feasible with the older elastic methods. Much of the final chapter which deals with the assumptions and aims of plastic design is of considerable interest to the practical designer.

M. Holmes

\section{OCEANIC CRUSTS}

\section{An Introduction to Marine Geology}

By M. J. Keen. (The Commonwealth and International Library of Science, Technology, Engineering and Liberal Studies: Geophysics Division.) Pp. ix +218 . (Pergamon Press: Oxford, London and New York, 1968.) $42 s$ boards; 30s flexi-cover.

INTEREST in marine geology has increased enormously in the past ten years. Literature on this subject is not very extensive and this book is very timely. The book has been written primarily for those people who are not specialists in the subject so as to give them an insight into what geologists and geophysicists get up to at sea and what they have found out so far. I think, however, that even the experts will find this a useful summary of our knowledge of marine geology and geophysics apart from the very recent developments in this rapidly expanding subject.

For those people who are not geologists, the author begins with an account of the main rock types found on the Earth and then goes on to describe briefly the techniques used by geophysicists to explore the ocean floor. The following chapters deal with the subject in the order in which our knowledge of the oceans has grown. The author starts with topography which is, of course, the easiest type of information to collect but which has, nevertheless, given many clues to the structure beneath. He then continues with the sedimentary layers in the ocean and includes in this section a description of the technique for determining the absolute age of rocks by measuring the decay of radioactive elements in them.

The last four chapters deal with that part of the subject which has been most recently investigated, and where our knowledge of the subject is increasing most rapidly, namely, recent ideas on the nature and relationship of oceanic and continental crust. Finally, there is an excellent list of references which should prove useful to those who want to investigate the subject further. F. GRAY

\section{RUSSIAN SOIL SCIENCE}

\section{Theory of Soil Moisture}

Vol. 1: Moisture Properties of Soils and Movement of Soil Moisture. By A. A. Rode. Translated from the Russian. Pp. $x+560$. (Israel Program for Scientific Translations: Jerusalem May 1969. Distributed in the UK by H. A. Humphrey: London.) $166 s$.

Hitherto, most English-reading workers have had to depend on inadequate abstracts to get any idea of what is going on in Russian soil science. Now, in what seems to be an excellent translation, we have from the doyen of the world's soil physicists a very long account of Russian achievement in the study of soil water, with a second volume to follow, more explicitly concerned with field problems. In the collected references there are twenty-two pages from Russian sources and fourteen from outside, giving two causes for satisfaction. First, the scale of Russian activity is revealed, and Dr Rode, choosing largely Russian examples to illustrate his arguments, gives many new facts in useful tables and diagrams for an extremely wide range of soil types. Second, it is clear that there is no lack of awareness of outside ideas, and where there is a difference in philosophy it is a deliberate choice, not caused by ignorance of a possible alternative. That there is a difference has long been known, and the book emphasizes it. One of Rode's own major papers is on "Different Types of Water Regimes in Soils", and in his list of soil moisture "constants" he has eleven entries. This kind of approach to soil water was common 30 or 40 years ago, but most of the rest of the world has since preferred to restrict the number of con. stants to two or three, and to treat the physical properties of water in soil as continuously variable from saturation to dryness. Perhaps in this simplification we have missed something: the second volume may show us.

Much of the book is about unsaturated soil. More than once Rode refers to a "practically water saturated atmosphere" at 94 per cent relative humidity, which is a fair statement for an experiment range that starts near zero, but not for plant growth, where the important range is from 98 to 100 per cent. To get to know the raw material properly, of course, the whole range must be covered: this, the primary task of research, is well done by Rode. As examples, there are good extended surveys of adsorption isotherms, and of hydraulic conductivity, with facts and theories from both Russian and foreign sources.

The theoretical treatment is generally good-teachers will find much in it that is helpful-though in places. simple ideas are worked out at too great a length, and in others an important result is quoted without explanation. There are occasional protests against the use of "ideal" soils and of simple models by foreign physicists and mathematicians, but, fortunatcly, Rode has no hesitation in ignoring his own protests and simplifying to the limit in order to get a physical idea established. His use of "Theory" in the title presumably absolves him from any" responsibility for discussing measurements in terms of either technique or accuracy, but there are discussions where the critical reader might be rather more concerned with the accuracy of the measurements than with the plausibility of the hypothesis set up to explain them.

There is no index, either to subjects or authors, and the 50 or 60 entries in the table of contents are quite inadequate for a book of this length.

In his conclusion, Rode himself draws attention to the difference in outlook between the Russian school and other workers, "mainly abroad". By coincidence, one of the other workers has just published a book on the same subject (An Introduction to the Physical Basis of Soil-Water Phenomena, reviewed in Nature, 223, 1080: 1969), and anybody interested in either the physics or the philosophy must make sure they have easy access to both books.

H. L. Penman

\section{VERTEBRATE ANATOMY}

\section{Morphologie Évolutive des Chordés}

By Paul Pirlot. Pp. xxxii +1068. (Les Presses de l'Université de Montréal: Montréal, 1969.) n.p.

Pirlot is a professor in the University of Montreal. His book is primarily designed to provide a text in French for use in the universities of the French-speaking regions of Canada, which at present use American textbooks. Because he feels that these books have developed the best technique for introducing vertebrate comparative anatomy to students, Professor Pirlot has adopted a similar plan for his book. It is then, by intention, extremely similar to such textbooks as Romer's Vertebrate Body. This is so familiar to most English-speaking workers that it seems both fair and convenient to use it as a yardstick for comparison.

Pirlot's book is slightly wider in its scope, including the hernichordates, urochordates and cephalochordates as well as the vertebrates. On the other hand, unlike Romer, he does not deal with basic aspects of biochemistry and cellular morphology, and his section on the classification of the vertebrates is very much briefer than Romer's. 